LAWRENCE LIVERMORE N A T IO N A L LABORATORY

\title{
Studies on Bacteria-Like Particles Sampled from the Stratosphere
}

M.Wainwright, P.K.Weber, J.B.Smith, I.D Hutcheon, B.Klyce, N.C.Wickramasinghe, J.V. Narlikar, P.Rajaratnam

July 28, 2004

Aerobiologia 
This document was prepared as an account of work sponsored by an agency of the United States Government. Neither the United States Government nor the University of California nor any of their employees, makes any warranty, express or implied, or assumes any legal liability or responsibility for the accuracy, completeness, or usefulness of any information, apparatus, product, or process disclosed, or represents that its use would not infringe privately owned rights. Reference herein to any specific commercial product, process, or service by trade name, trademark, manufacturer, or otherwise, does not necessarily constitute or imply its endorsement, recommendation, or favoring by the United States Government or the University of California. The views and opinions of authors expressed herein do not necessarily state or reflect those of the United States Government or the University of California, and shall not be used for advertising or product endorsement purposes. 


\section{Studies on bacteria-like particles sampled from the stratosphere}

M.Wainwright ${ }^{a *}$, P.K.Weber ${ }^{b}$, J.B.Smith ${ }^{\text {b I.D }}$ Hutcheon $^{b}$ B.Klyce ${ }^{c}$ N.C.Wickramasinghe ${ }^{d}$, J.V. Narlikar ${ }^{\mathrm{e}}$, P.Rajaratnam ${ }^{\mathrm{f}}$,

${ }^{a}$ Department of Molecular Biology and Biotechnology, University of Sheffield, Sheffield S10 2TN, UK; ${ }^{b}$ Lawrence Livermore National Laboratory, P.0. Box 808 Livermore, CA 94550, USA, ${ }^{c}$ Astrobiology Research Trust, Memphis, TN 38111, USA; ${ }^{d}$ Cardiff Centre for Astrobiology, 2, North Rd, Cardiff, CF10 3DY, UK; ${ }^{e}$ Inter-University Centre for Astronomy and Astrophysics, Post Bag 4, Gamashkind, Pune, 411 007, India; ${ }^{f}$ Indian Space Research Organisation, Antariksh Bhavan, New Bell Rd, Bangalore, 560094, India,

(*author for correspondence, email: m.wainwright@sheffield.ac.uk.)

Key words: astrobiology, panspermia, scanning electron microscopy, stratosphere, SIMS

\section{Abstract}

Bacteria-like particles recovered from the stratosphere and deposited on cellulose acetate membranes have been analysed to confirm their bacterial nature. One particle appeared to be attached to an inorganic 
particle apparently by mucoid material

typically produced by bacteria. A filamentous structure, morphologically similar to a fungal hypha, was also observed. EDS analysis showed that the particles were all nonmineral and therefore could be biological in nature. However, the composition several clumps of nanobacteria-sized particles were found, by SIMS analysis, to be inconsistent with that of bacteria. The results show that it is dangerous to assume that bacteria-like particles seen under scanning electron microscopy are necessarily bacteria.

\section{Introduction}

Because of obvious sampling difficulties, there have been relatively few studies on the microbiology of the stratosphere. Russian workers, using rockets to sample the stratosphere at heights of $48-77 \mathrm{~km}$ claimed to have cultured a range of bacteria and fungi (Imshenenetsky, et al., 1978). More recently, using balloon-carried cryosamplers, Wainwright et al. (2003, 2004) have shown that bacteria are present in atmospheric samples collected at a height of $41 \mathrm{~km}$. Here, we report scanning electron microscope (SEM) studies of stratospheric particles possessing biological morphologies. Energy dispersive Xray spectroscopy (EDS) and SIMS analysis were used to investigate whether these bacterialike particles are actually biological. 


\section{Materials and Methods}

Stratospheric air was sampled using a balloon at a height of $41 \mathrm{~km}$ and transferred to $0.2 \mu \mathrm{m}$ cellulose acetate filters described by Wainwright et al. (2003). The membranes were then gold coated and examined by scanning electron microscopy (SEM)using a Phillips ESEM XL3O scanning electron microscope with a field emission gun; the elemental composition of the particles was determined using a Prism EDS X-ray detector.

Secondary ion mass spectrometry (SIMS) was performed using the Lawrence Livermore National Laboratory Cameca NanoSIMS 50. The ${ }^{133} \mathrm{Cs}^{+}$primary beam had a $50 \mathrm{~nm}$ diameter. The mass spectrometer was tuned for simultaneous detection of ${ }^{12} \mathrm{C}^{-},{ }^{13} \mathrm{C}^{-},{ }^{12} \mathrm{C}^{14} \mathrm{~N}^{-},{ }^{12} \mathrm{C}^{15} \mathrm{~N}^{-}$, and ${ }^{31} \mathrm{P}^{-}$. $\mathrm{N}$ is detected as $\mathrm{CN}$. Samples were located first by SEM and relocated in the NanoSIMS using real-time secondary electron imaging. Analyses were performed on control bacteria (a species of Bacillus) for sample comparison.

\section{Results and Discussion}

A variety of bacteria-like particles having the dimension of normal bacteria (i.e. in excess of $0.5 \mu \mathrm{m})$ were observed on the membrane on which particles from the stratosphere had been deposited Fig.1a.for example, shows an oval, bacteria-like particle. Except for its collapsed appearance (not usually associated with inorganic 
particles), this particle, like most others observed, possesses no morphological characteristics (e.g. flagellae or fimbriae) that are typically associated with bacteria. The coccoid-shaped particle shown in Fig. $1 \mathrm{~b}$. is perhaps more convincingly bacterial because it is attached to an inorganic particle by what appears to be mucoid material, typically produced by bacteria.(c (crystals of similar inorganic particles were subsequently shown by EDA analysis to consist of zirconium and chlorine) Such bacterialike characteristics provide more suggestive, but not conclusive, evidence that this particle is bacteria in nature. A mass of bacteria-like nano-particles, some appearing as appendages is shown in Fig.1c. Such a clump could be regarded as being nanobacteria, but again, no typically bacterial structures are present to aid confirmation of this possibility. Very few filamentous organisms having morphologies similar to microorganisms are seen in stratospheric air samples. An exception is shown in Fig.2. Here, a filament with a rounded tip is seen emerging from a particle mass. Although spores are not present, this filament is morphologically similar to a fungus, or possibly a filamentous bacterium. The thickness of the filament might appear to indicate the latter. However, microorganisms surviving in the extreme environment of the stratosphere will exposed to low nutrient conditions which would tend to induce coccoid cells to become smaller, and make filamentous organisms 
thinner than laboratory-grown bacteria and fungi.

Scanning electron microscope studies have been widely used in microbial ecology, often somewhat uncritically. For example bacterialike structures found in soils and waters have been assumed to be bacteria in the absence of further defining analysis. Claims that bacteria exist in the stratosphere clearly require exacting standards of evidence. To this end, the particles seen in our very limited sample were examined using EDS analysis. Unfortunately it was not possible to confirm that the particles consist of carbon, so this had to be inferred by the fact they were not clearly inorganic. Electron dispersive X-ray analysis of nonbacteria like particles from the atmosphere generally shows them to be rich in calcium iron or silicon, or (like the particle shown in Fig.1b.) more exotic metals such as zirconium. The bacteria-like particles in contrast are not rich in these elements. From this it can be concluded that the bacterialike particles are not mineral in nature. For further confirmation of this, we analysed clumps of bacteria-like particles by SIMS. Because of the relative difficulty of locating particles of interest, only three bacteria-like masses (e.g. the one shown in Fig.1d) were analysed. These three were of particular interest because they are morphologically similar to nanobacteria. Previously, wainwright et al. (2004) provided presumptive evidence for the presence of 
nanobacteria in these stratospheric samples, a conclusion based on the apparent presence of fimbriae on one of the particles. The EDS spectrum of the particle mass shows that it was not mineral in nature (Fig.3.). SIMS analysis however, showed that the $\mathrm{C}$ and $\mathrm{CN}$ count rates were significantly below count rates found for control bacteria, and that the $\mathrm{CN} / \mathrm{C}$ ratio of the particle mass is not typical of an organic sample. Therefore, this particle is not a clump of nanobacteria. This of course does not mean that all of the bacteria-like particles, reported here, and elsewhere, are artefacts. It merely that in the absence of defining characteristics (such as fimbriae or flagella), it is dangerous to assume that particles with bacteria-like morphologies always bacteria.

The use of the NanoSIMS is potentially of considerable benefit, since it can be used to analyse isotopic ratios, that may indicate whether a bacteria isolated from the stratosphere originates from Earth or space. It is worth noting that the choice of membranes onto which any stratospheric particles are deposited is best made with NanoSIMS analysis in mind during the initial design of the experiment. Here, cellulose acetate membranes, typically employed by microbiologists, were used. Unfortunately, these did not withstand the full period of nano-SIMS analysis. As a result, in future studies, stratospheric particles will be collected, or deposited, on more durable gold membranes. 
In conclusion, we have demonstrated that several masses of stratospheric particles possessing bacteria-like morphology are not biological. This does not of course mean that all of the observed particles seen were of a similar nature; certainly particles possessing bacteria-like structures are probably biological and warrant further study. Finally, these results emphasize that SEMbased morphological characteristics alone cannot be used to confirm the presence of bacteria in stratospheric samples. This caveat applies to more routinely sampled environments, such a soils and water, where SEM-based morphology is often the sole criterion used for identifying bacteria.

\section{References}

Imshenetsky, A.A., Lysenko, S.V. and Kazakov,G.A. (1978). Upper boundary of the biosphere Appl.Environ.Microbiol., 35, 1-5

Wainwright, M. , Wickramasinghe, N.C., Narlikar, J . V.and Rajaratnam, P. (2003) Microorganisms cultured from stratospheric air samples obtained at 41k. FEMS Microbiol.Let. 218, 161-165.

Wainwright, M., Wickramasinghe, N.C.,

Narlikar, J.V. and Rajaratnam P. (2004) Are these stratospheric nanoparticles bacteria? Microbiology 150, 756-758. 
Figures

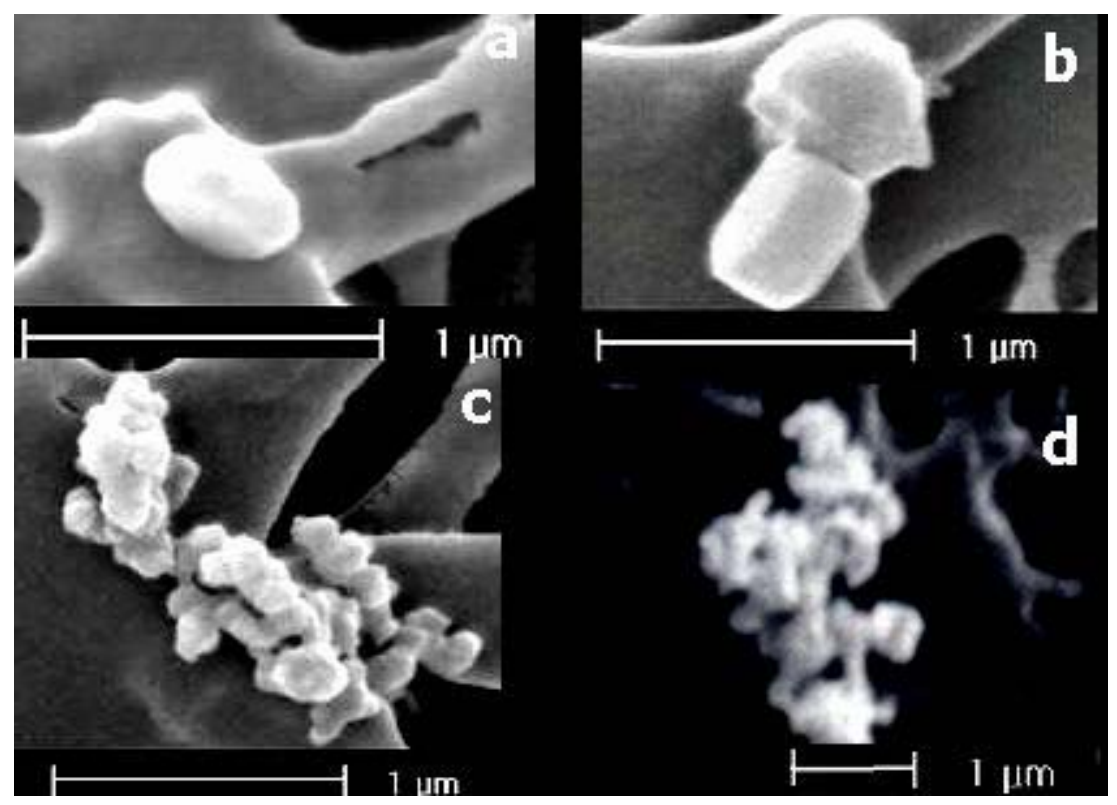

Fig. 1. Bacteria-like particles from the stratosphere(at a height of $41 \mathrm{~km}$ ).

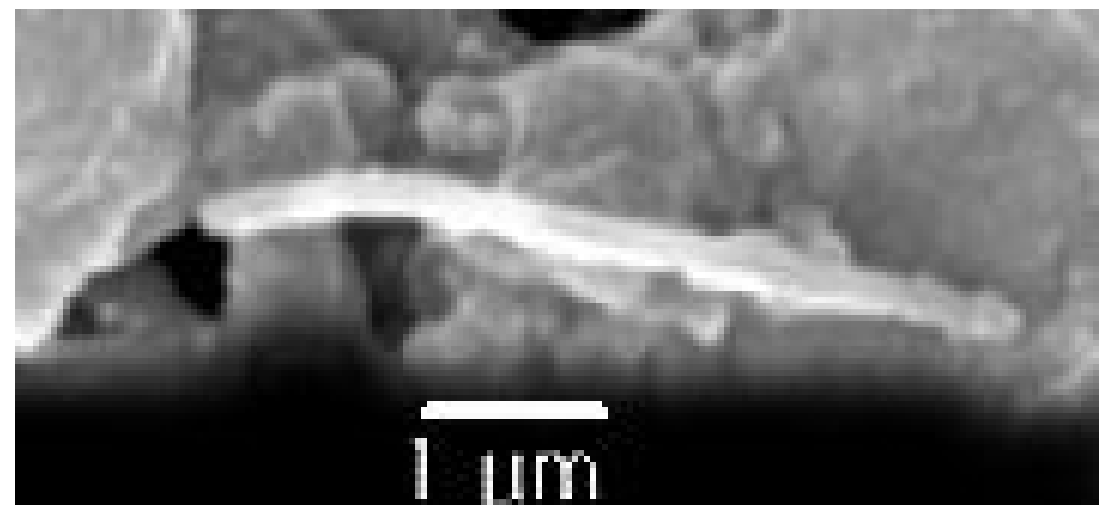


Fig.2. A stratospheric filament, morphologically similar to a fungus.
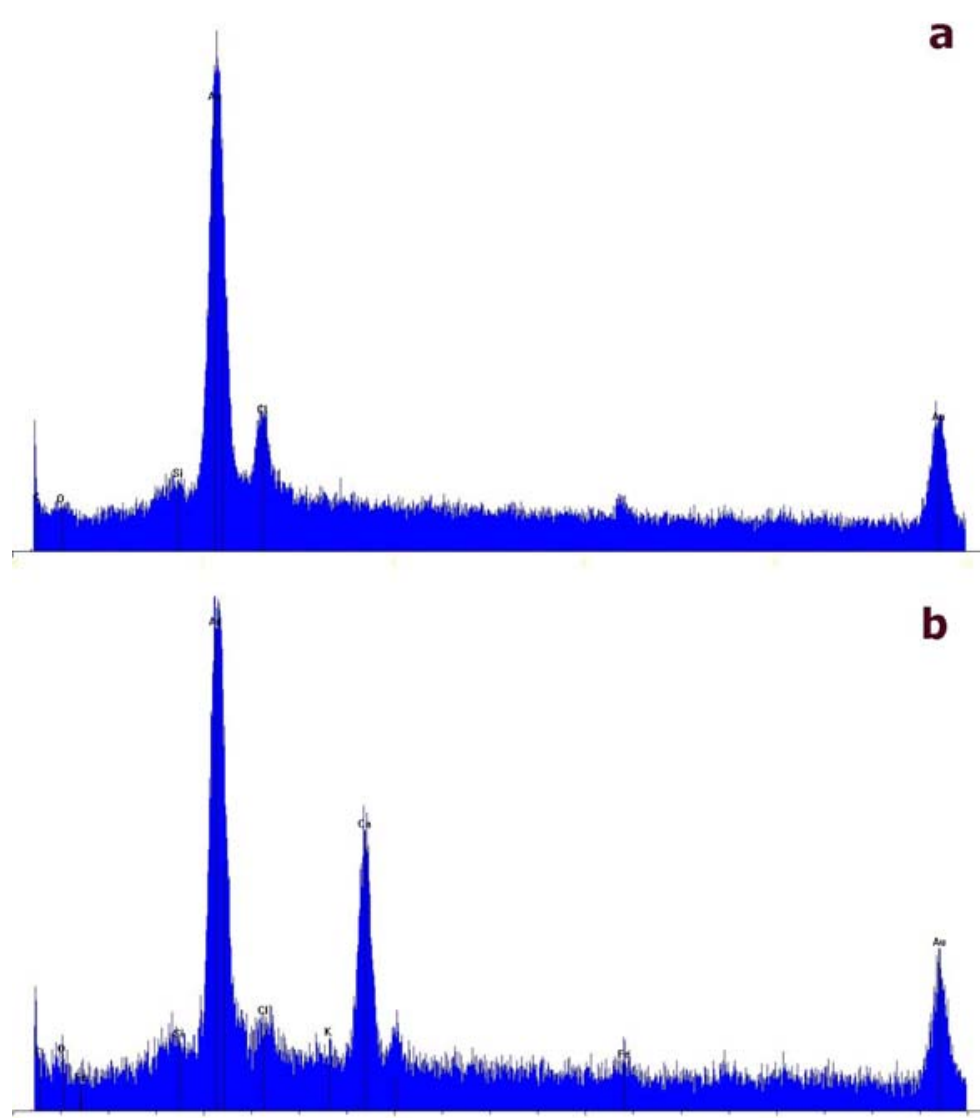

b

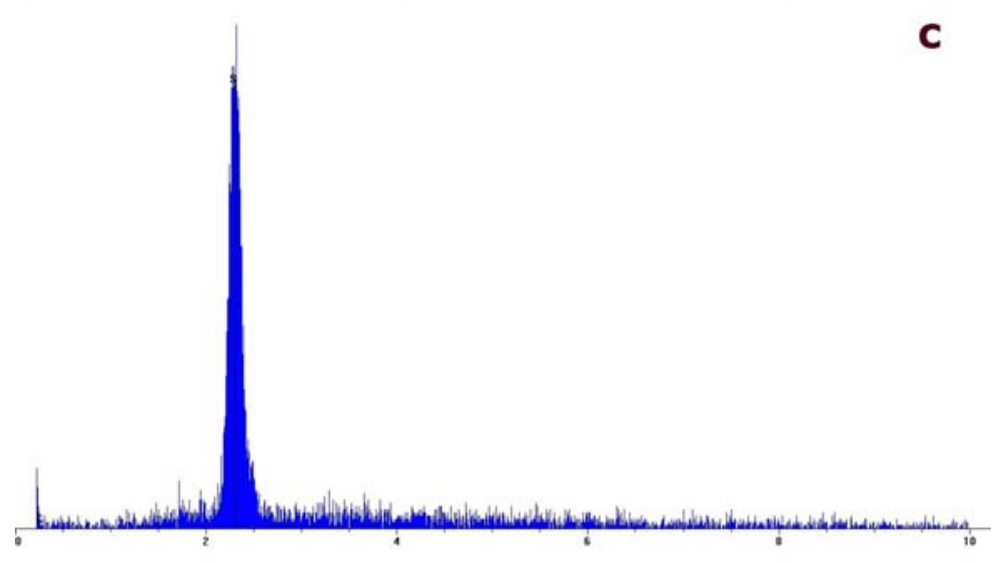

Fig. 3. Typical EDA analysis of the particles obtained at $41 \mathrm{~km}$ a)analysis of a typical 
bacteria-like particle; b)analysis of a typical inorganic-like particle; c)analysis of the control membrane. 